\title{
THE DEVELOPMENT OF AN ICT FRAMEWORK FOR BUSINESS INTELLIGENCE AT THE BRAZILIAN NATIONAL CANCER INSTITUTE: A CASE STUDY OF ORGANIZATIONAL LEARNING AND INNOVATION \\ O DESENVOLVIMENTO DE UMA PLATAFORMA DE TIC PARA INTELIGÊNCIA DE NEGÓCIOS NO INSTITUTO NACIONAL DO CÂNCER: UM ESTUDO DE CASO SOBRE APRENDIZAGEM ORGANIZACIONAL E INOVAÇÃO
}

Antônio Augusto Gonçalves ${ }^{1}$ José Geraldo Pereira Barbosa ${ }^{2}$

\section{ABSTRACT}

This paper presents the development of an ICT framework for the management, processing and analysis of large-scale Brazilian cancer data. This was a qualitative and descriptive study conducted at Brazilian National Cancer Institute (INCA). The benefits derived from the framework implementation, so far, are: real-time knowledge access; patient's focus and satisfaction; enhanced knowledge transfer and diffusion of best health care practices; reduction in treatment costs; relief of the INCA's labor shortage; and finally speediness of cancer diagnosis and enhanced quality of both diagnosis and data used in epidemiological studies. The study also identifies the critical aspects that must be observed by the Brazilian health organizations in early stages of development of BI systems and thus contributes to the faster adoption of such systems.

Keywords: health care; information and communication technology; service innovation; organizational learning; public administration

\footnotetext{
1 Possui graduação em Engenharia Civil pela Universidade Federal de Juiz de Fora, mestrado em Engenharia de Produção pela Universidade Federal do Rio de Janeiro e doutorado em Engenharia de Produção pela Universidade Federal do Rio de Janeiro. Professor do programa de Mestrado em Administração e chefe da área de Tecnologia de Informação do Instituto Nacional do Câncer. Rio de Janeiro. Rio de Janeiro. Brasil.E-mail: augusto@inca.br

2 Possui graduação em Engenharia Naval pela Escola Politécnica da Universidade de São Paulo, Mestrado em Aerospace Engineering Georgia Institute of Technology, Mestrado e Doutorado em Administração pelo Instituto COPPEAD de Administração/UFRJ. Coordenador e professor do Mestrado em Administração e Desenvolvimento Empresarial da Universidade Estácio de Sá (MADE/UNESA). Rio de Janeiro. Rio de Janeiro. Brasil. E-mail: jose.geraldo@estacio.br
} 


\section{RESUMO}

Este estudo apresenta o desenvolvimento de uma plataforma de TCI a ser utilizada no gerenciamento, processamento e análise de dados brasileiros em larga escala sobre a doença do câncer. Trata-se de um estudo de abordagem qualitativa e finalidade descritiva desenvolvido no Instituto Nacional de Câncer (INCA). Os benefícios decorrentes da implementação da plataforma são, até o momento: acesso ao conhecimento em tempo real; foco e satisfação do paciente; melhoria da transferência de conhecimento e difusão das melhores práticas de cuidados de saúde; redução dos custos de tratamento; alívio da mão de obra do INCA; e, finalmente, mais velocidade no diagnóstico de câncer e melhor qualidade de diagnóstico e dados utilizados em estudos epidemiológicos. O estudo também identifica os aspectos críticos que devem ser observados pelas organizações de saúde brasileiras em estágios iniciais de desenvolvimento de sistemas de $\mathrm{Bl}$ e assim colabora para a adoção mais rápida de tais sistemas.

Palavras-chave: serviços de saúde; tecnologia de informação e comunicação; inovação de serviços; aprendizagem organizacional; administração pública

\section{INTRODUCTION}

Cancer is the second leading cause of death in Brazil. There have been approximately 500.000 new diagnoses of cancer each year, and the vast majority of these patients have had some contact with hospital services. However, research also shows that in several regions of the country long waits for diagnostics and treatments have become routine, which leads to a situation that people have being diagnosed with cancer at a very advanced stage. These sad findings have moved the national health care ministry, in recent years, to start a series of challenging reforms in order to implement early diagnosing clinical procedures.

The huge number of cancer cases in Brazil means that the disposal of information about the disease is crucial for patients and clinicians involved in their care, and those with cancer services responsibility, what opens an opportunity window for implementing a framework for business intelligence into the Brazilian National Cancer Institute. Being responsible for the prevention and control of cancer in Brazil, the Brazilian National Cancer Institute (INCA - Instituto Nacional de Cancer) develops actions, campaigns and programs nationwide in compliance with Brazilian National Health Policy. The Institute also plays an important role in the international arena through technical cooperation agreements with foreign entities and organizations, making part of international networks of collaboration.

The development of information systems that support the continuing evaluation of early detection programs is among the priorities in Brazil's cancer control. The strategic importance of clinical data usage has motivated INCA in adopting electronic medical record and implementing Information and Communication Technology (ICT) applications as decision support tools for strategic decision making.

This paper presents the development of an ICT framework for business intelligence platform employed on the management, processing and analysis of large-scale Brazilian cancer data, and the main benefits for cancer disease management derived from its implementation. To some extent, this study is the continuation of a research conducted at INCA five years ago, by the same authors, in order to propose a conceptual framework for a knowledge management system in the Brazilian National Cancer Institute. The study aims to identify the critical aspects that must be observed by the Brazilian health organizations in early stages of development of BI systems and thus to contribute to the faster adoption of such systems.

Presently, in hospital environments, ICT has been used primarily as a management tool, in particular by facilitating the collection and presentation of data and improving communica- 
tion between the workforce. These important features fall short of the potential of technology. Therefore, the study also aims to demonstrate the possibilities of ICT as a tool for organizational learning and indicate the usefulness of ICT as a facilitator of health innovations.

\section{BUSINESS INTELLIGENCE IN HEALTHCARE}

The delivery of healthcare has always been information intensive. Business intelligence (BI) systems are designed to deliver decision-support information and have been continually shown to provide value to organizations (Rohloff, 2011). A useful function of $\mathrm{Bl}$ is to integrate data from a wide variety of internal and external sources, consequently providing an information platform for healthcare decision makers (Mettler and Vimarlund, 2009).

Organizations in industries outside healthcare have been able to prove that an effective application of Business Intelligence (BI) and analytical tools leads to a competitive advantage. Healthcare organizations are definitely using $\mathrm{BI}$ and analytical tools to support their financial and operational functions. Therefore, the adoption of electronic health records and other investments in health information technology have a great potential to transform clinical care. (Giniat, 2011)

$\mathrm{BI}$ is very useful and is seen as a new frontier of data mining. So BI technology platforms are gaining importance in the healthcare domain as a consequence of their capability to improve managerial decisions in this complex business environment, allowing managers lead their organizations in the most efficient way and deliver individualized products and services (Fickenscher, 2005).

Advances in information technology will help healthcare managers establish the basis for fundamental changes within the healthcare organization. Besides allowing the physicians to communicate easily and quickly with patients and staff members; it will also increase community' awareness about healthcare through online healthcare forums and other health information systems. (Lester, 2007).

Despite these great benefits, the majority of healthcare organizations has not yet implemented BI systems (Hanson, 2011). After all the design and implementation of an integrated data warehouse is a resource-intensive process requiring a multidisciplinary approach and substantial investments. (Berndt, 2003)

However, the implementation of a ICT framework for business intelligence should consider the organization's operating model and the stage of maturity of the IT management of that organization. Regarding the level of development and control of IT management strategies, Ross, Weill and Robertson (2008) have classified them into four stages of maturity: business silos architecture; standardized technology architecture; optimized core architecture, and business modularity architecture. In particular, in the case of the standardized technology stage, the main objective is to reduce IT costs through the implementation of standardized technology platforms (hardware and software). The companies transfer part of their IT investments in local applications to a shared infrastructure, at which stage they adopt standardized technology to reduce the number of platforms they run.

\subsection{THE ICT FRAMEWORK AS AN ORGANIZATIONAL LEARNING TOOL}

Healthcare organizations are characterized by a rising level of specialized departments, medical disciplines and care services which are gradually dispersed across organizations within healthcare networks. Healthcare processes, therefore, are increasingly executed according to a wide range of disseminated activities, performed by the collaborative effort of professionals with different skills, knowledge and organizational culture. (Lenz, 2004) 
In order to provide the right information at the right time to the right decision makers in the right manner, health care organizations are implementing data warehouse applications as decision support tools for strategic decision making. As health care organizations become more computerized by adopting a wide range of information technologies, an immense amount of information is captured in multiple databases. Extracting, analyzing, and presenting this information in a useful real-time method can help improve the quality, safety and efficiency of health care delivery. Management can also save money by implementing more efficient clinical pathways and convincing physicians to adopt best practices based on evidence-based medicine. (Shams, 2001)

A variety of decision support capabilities will be necessary to increase the productivity of medical personnel, analyze care outcomes and continually refine care delivery processes to remain profitable while holding costs on line and maintaining quality of care. (Dutta and Heda, 2000)

Health care data warehouses, which integrate data from many operational systems and provide longitudinal view of health information, are becoming progressively more common. Healthcare decision support is faced with the challenges of complex and diverse data and knowledge formats and tasks. These challenges are compounded by the lack of standardized terminology in IT, compared to other scientific fields, the rigorous performance and accuracy requirements and the prevalence of legacy systems. (Sheng, 2000)

Despite the uncertainty about the business value of ICT investments, healthcare organizations will be in need of acquiring expertise and technology for business intelligence (BI) in order to comply with legal requirements to gather systematic performance information.

Nowadays, decision makers are facing a growing demand for both clinical and administrative information in order to comply with legal and costumer requirements. The use of business intelligence $(\mathrm{BI})$ is seen as a possible solution to this present challenge.

According Delen, Walker and Kadam (2005), clinical databases have accumulated large amounts of information about patients and their medical conditions. Associations and patterns within this data could provide new medical knowledge. Data mining is a data extraction technique which can be used to explore information or knowledge from a large amount of data. Studies have applied this method to discover unknown associations in healthcare as the case of prediction of the survival rate of breast cancer. Similarly Bach (2003) states that data mining approaches using decision trees, artificial neural networks, and other artificial intelligence techniques can discover new information and relationships embedded in large, complex datasets by inductively learning new patterns and relationships.

Data mining combines techniques of description and prediction. Description aims to find patterns by establishing associations while prediction seeks to forecast some response of interest. Predicting the outcome of a disease is one of the most interesting and challenging tasks in which to develop data mining applications. Survival analyses is a field in medical prognosis that deals with application of various methods to historic data in order to predict the survival of a particular patient suffering from a disease over a particular time period. (Delen, Walker and Kadam, 2005)

Data Warehouses act as a repository for current and historical operational data. The health care industry has a poor record in terms of standardization; therefore data are widely used (and misused) in an ad hoc manner. The knowledge data warehouse [KDW] allows the information to be presented in several formats and to be distributed more widely in communities of practice. At the same time, Online Analytic Processing[OLAP] functionality can be used to gain a deeper understanding of specific health care issues. For Bose (2003), the Knowledge Data Warehouse [KDW] provides the means for business intelligence through ad hoc and managed query environment, OLAP support, statistical analysis tools, knowledge mining and access to Decision Support Systems [DSS] applications. 
The Data Mining [DM] and Decision Support System [DSS] are among the tools used by physicians to gain access to KDW. These tools provide the means for business intelligence through ad hoc and managed query environment, statistical analysis tools, knowledge mining (answers that lead to new questions), and access to decision support software at all hierarchical levels. Goebel and Gruenwald (1999) argue that knowledge-mining tools are used to recognize patterns and relationships that may be valuable for building models that support clinical analysis and capacity analysis. These tools improve the decision-making process by providing new information that otherwise users would not have been able to access on a timely basis. The newly extracted knowledge needs to be inserted into one or more bases to keep them continuously up-to-date and to be of good use for the practice of evidence-based medicine. Data visualization techniques that facilitate the interpretation process of new knowledge can be used in conjunction with the knowledge data warehouse.

Knowledge discovery is the extraction of implicit information from a dataset. Knowledge extracted from a dataset refers to a set of rules that are implicit, valid, potentially useful, and those that are easily comprehensible by humans. (Fayyad. 1996) Therefore Knowledge Data Discovery (KDD), which includes data mining techniques, has become a popular research tool for medical researchers who seek to identify and exploit patterns and relationships among large number of variables, and be able to predict the outcome of a disease using the historical cases stored in data warehouses. (Richards, 2001)

\subsection{THE ICT FRAMEWORK AS AN INNOVATION FACILITATOR IN HEALTHCARE PROCESS}

Healthcare organizations are under growing pressure to look for innovations to ensure that their scarce resources are used efficiently to guarantee high quality patient care. (Hanson, 2011) So, in addition to supporting organizational learning, the ICT framework has an important role in the process of innovation in organizations. Healthcare innovation can vary from new drug therapies and surgical procedures, to innovative forms of professional health training, patient education, management, financing and service delivery models. (Varkey, Horne and Bennet, 2008) The following paragraphs present considerations on the role of ICT in the process of innovation in healthcare.

To Barras (1986) innovation in services constitutes what he called "reverse product cycle". The three steps of the reverse product cycle would be: (i) ICT applications are initially designed to improve the efficiency and delivery of existing services, (ii) technology is applied to improve the quality of services, and (iii) finally the technology generates new services.

Hull and Tidd (2003) propose a model for the process of innovation in services, where the operational core is composed of a trio of interdependent organizational elements: Early simultaneous involvement (cross-functional teams), In-process design controls (rapid, reiterative redesign strategy) and Information and communication technology support. Hull (2004) adds that the support of ICT not only includes the use of tools for design and product development, but also to support communication and collaboration across the value chain.

According Demirhan, Jacob and Raghunathan (2006), the use of new information technology applications, such as knowledge management and business intelligence systems, allow developers to access innovation projects already implemented, allowing them to learn from previous experiences and update their current strategy. Thus organizations are able to develop new products that best fit market demand and offer better services to meet customer needs.

Tidd, Bessant and Pavitt (2005) argue that the trajectory of technological innovation in organizations depends on the economic sector in which the business is located. For these authors, social and public services such as health, education, public administration, among others, 
would be led by suppliers. Sources of technology would be mainly providers of equipment and other productive inputs and the learning in usage. In the case of the health sector, suppliers of medical technology products and services and ICT would stand out. In particular, the authors highlight that ICT collaborates for flexible responses to users. According to Liaw (2002) most of the changes in the trajectory of medical practices evolve around ICT. Studies on innovation have showed that success and survival of the healthcare industry depend on the effectiveness and efficiency of ICT implementation.

In order to examine public sector services, Windrum and Garcia-Goñi (Windrum, Garcia-Goñi and Fairhurst, 2010) presents a multi-agent framework (see Figure 1) that includes policy-makers, public sector service providers (hospitals), firms (suppliers) and consumers (patients).

Figure 1: Multi-agent Framework for public services

Public Service Provider

Preferences and competences
User preferences and competences

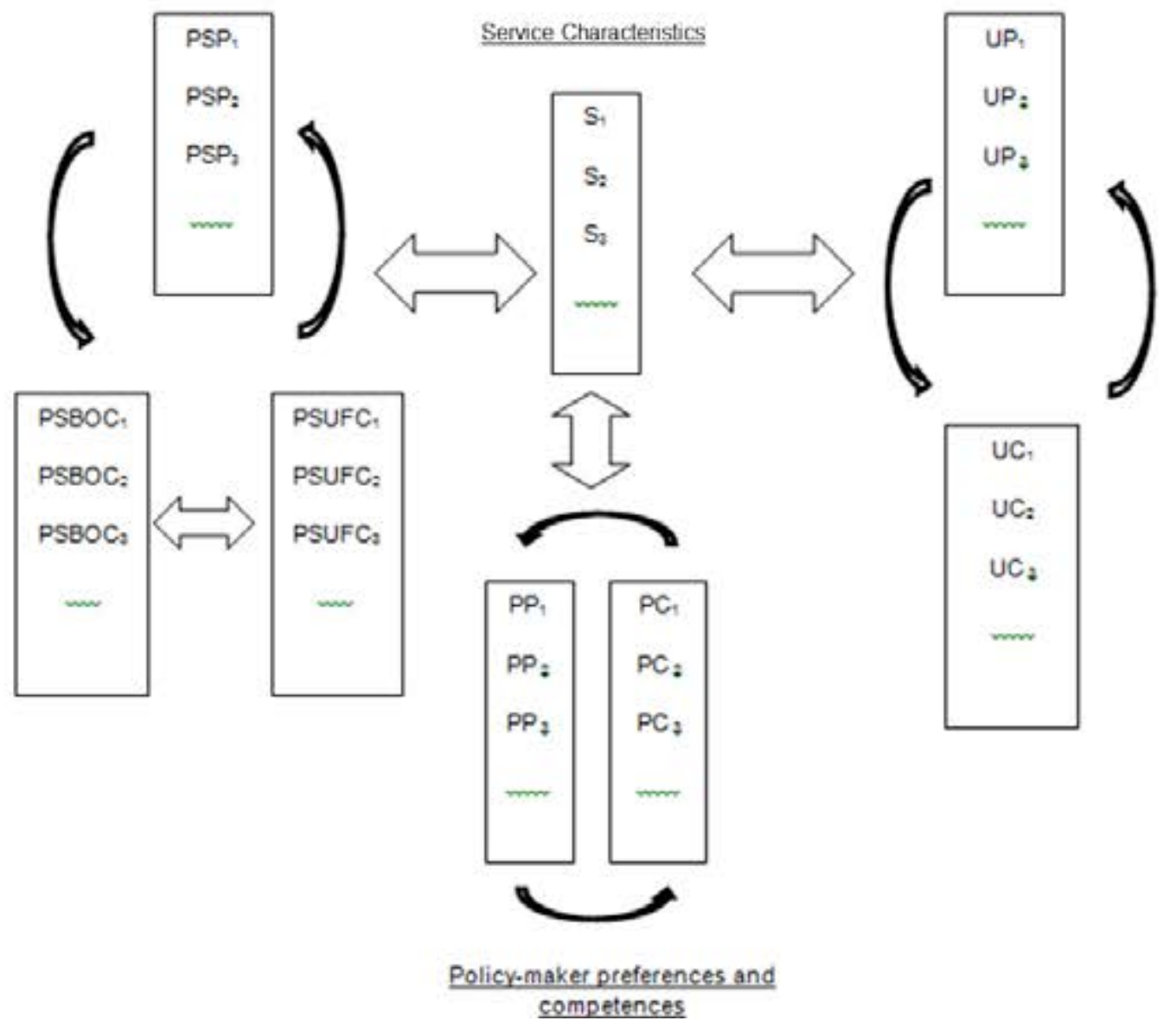

Source: adapted from Windrum, Garcia-Goñi and Fairhurst (2010)

Legend: S (Service Characteristics); PSP (Public Service Provider Preferences); PSBOC (Back-office Competence of Public Service Provider); PSUFC (User-facing Competences of Public Service Provider); PP (Policy-maker Preferences); PC (Policy-maker Competences); UP (User Preferences); UC (User Competences)

The model is very useful for understanding innovations in service sectors, such as healthcare, that have a relevant public sector dimension. (Windrum, Garcia-Goñi and Fairhurst, 2010:134-135) 
Different agents define their competences and preferences with respect to alternatives technologies and, thereby, reveal their interests. In turn, the development and diffusion of radically new innovations alters the competences bases and preferences of consumers, firms and policy-makers over time.

User-facing competences include all the tangible and intangible skills, know-how and technologies that are used to produce service characteristics. ... For example, in diagnosing and treating an illness such as cataracts, medical practitioners must have knowledge and skills in a set of interrelated hardware and software technologies in order to provide the final medical service to the patient. Back-office competences are the skills and administrative activities such as payroll and patient booking systems that support these user-facing competences and activities.

The third notable feature of the model is that it captures all five types of innovation discussed by Schumpeter $(1934,1943)$ : organizational, product, market, process and input innovations. A radical innovation alters not only the dimensions of the service characteristics vector but also the competences and preferences of the agents involved in the innovation process. Hence, the model captures the central neo-Schumpeterian message of long run change. The multi-agent system changes qualitatively over time as new medical technologies facilitate the development of new services with new service characteristics, and the preferences and competences of agents change as these radical innovations diffuse.

Whatever the model of innovation process, Tidd and Bessant (2009) state that every innovation is the result of a process consisting of four phases: (i) the exploration of ideas: scanning the environment (internal and external) to identify and process potential ideas to be developed in innovation, (ii) selection of ideas: selecting among a set of potential ideas, those that will go ahead, (iii) implementation of the idea: implementing the idea through various stages of development to the final product and release it as a new product or service in markets or as a new process within the company, and (iv) learning: it aims to review experiences of success and failure in order to learn how to better manage the innovation process and capture relevant knowledge from experience.

In particular, the support of data warehouses is revealed more fully in the learning and exploration phases of the innovation process. The clarification of an idea requires multiple activities, such as literature searches in scientific technical documents, designing and carrying out experiments in different situations, data logging, analysis, comparisons, reviews, and several reformulations of the original idea. The diversity of the knowledge base present in innovative organizations stimulates creativity and increases the fertilization of new ideas, thus facilitating the prospecting phase. (Damanpour and Schneider, 2006)

Regarding the capture of explicit knowledge - an important step in the learning phase of the innovation process - it is largely focused on databases. For Nelson and Winter (1982), the reservoirs of organizational memory - rules and routines - are inference codes derived from organizational experience. As patterns of activity, they are also sources of competence and competitive advantage. The rules are written and can be enforced while routines are implied, inferred from practice, and remembered by 'doing'.

The organizational memory can be abstract or concrete. In its abstract dimension, it encompasses concepts and unstructured information that is present in the organizational culture and minds of its members. In turn, the concrete memory encompasses the concepts and structured information that can be represented by computerized files and records. (Walsh and Ungson, 1991; Walsh, 1995)

Finally, one can also argue that in the long term, the performance of a particular innovation - the ICT framework, as an example - can be verified in terms of the growth of their acceptance by users over the years following its introduction. According Rogers (2003), the format of the adoption curve (epidemic curve) and its direction (in terms of the adopter group profile), are influenced by several factors: (i) relative advantage: the degree to which an innovation is 
perceived as better than the product it replaces or competes. Financial and nonfinancial factors dictate such an advantage; (ii) compatibility: the degree to which an innovation is perceived as being consistent with the values, experience and present needs of potential adopters; (iii) complexity: the degree to which an innovation is perceived as being difficult to understand or use; (iv) ability to be experienced: an innovation that can be experienced is less risky for potential adopters and allows the "learning by doing "; and (v) visibility: the degree to which the results of an innovation can be seen.

\section{METHODOLOGY}

This study was developed through a qualitative research design to present a descriptive analysis of the ICT framework implemented into the National Cancer Institute (Instituto Nacional de Cancer [INCA]). This framework is expected to support both hospitals and the national oncology network, the implementation of which has been placed in the hands of the INCA. The development occurred in the period 2011-2012.

A holistic single-case study - the kind of research employed in this study - intends to contribute to the knowledge of organizational phenomena, presenting a contemporary description of the system implemented, using an empirical inquiry to answer the questions what, who, where and how (Cooper and Schindler, 2003; Yin, 2003). The investigation was to be descriptive in nature and it was believed that, through direct observation and semi-structured interviewing, the case study methodology would be the most valuable to describe the implementation process.

\section{INCA CASE STUDY}

The option of implementing a framework for business intelligence considered the fact that INCA has five specific hospital units with different directors but which share the same processes and technologies based on a common patient database and standardized information systems. Additionally, this initiative also agrees with the Institute's policy of seeking to implement standardized technology platforms (hardware and software) in order to reduce costs. Ultimately, the implementation of the data warehouse reflects the option of INCA for an operational model known as "coordination". Also it reflects an IT management in a stage of maturity known as "standardized technology" as defined by Ross, Weill and Robertson (2008).

INCA has multidisciplinary committees which discuss their patients' clinical approach. The medical experts go to different sources of information in order to make their decisions. First, they check whether their patients comply with existing guidelines. On the other hand, they can also select their therapeutic decisions based on the cases of patients that have undergone similar treatment in the past. It appears therefore that the health sector is quite intensive in information as stated by Rohloff (2011) and Mettler and Vimarlund (2009).

To support the physicians' activities, several tools, such as tracking mechanisms for keeping the longitudinal patient history, on-line tools for gathering clinical information and the traditional medical record, are used. Most of these are patient-centric and make the hospital environment amenable to the kind of knowledge management system framework, such as the one presented in Figure 2. 
Figure 2: ICT framework for Business Intelligence at the Brazilian National Cancer Institute

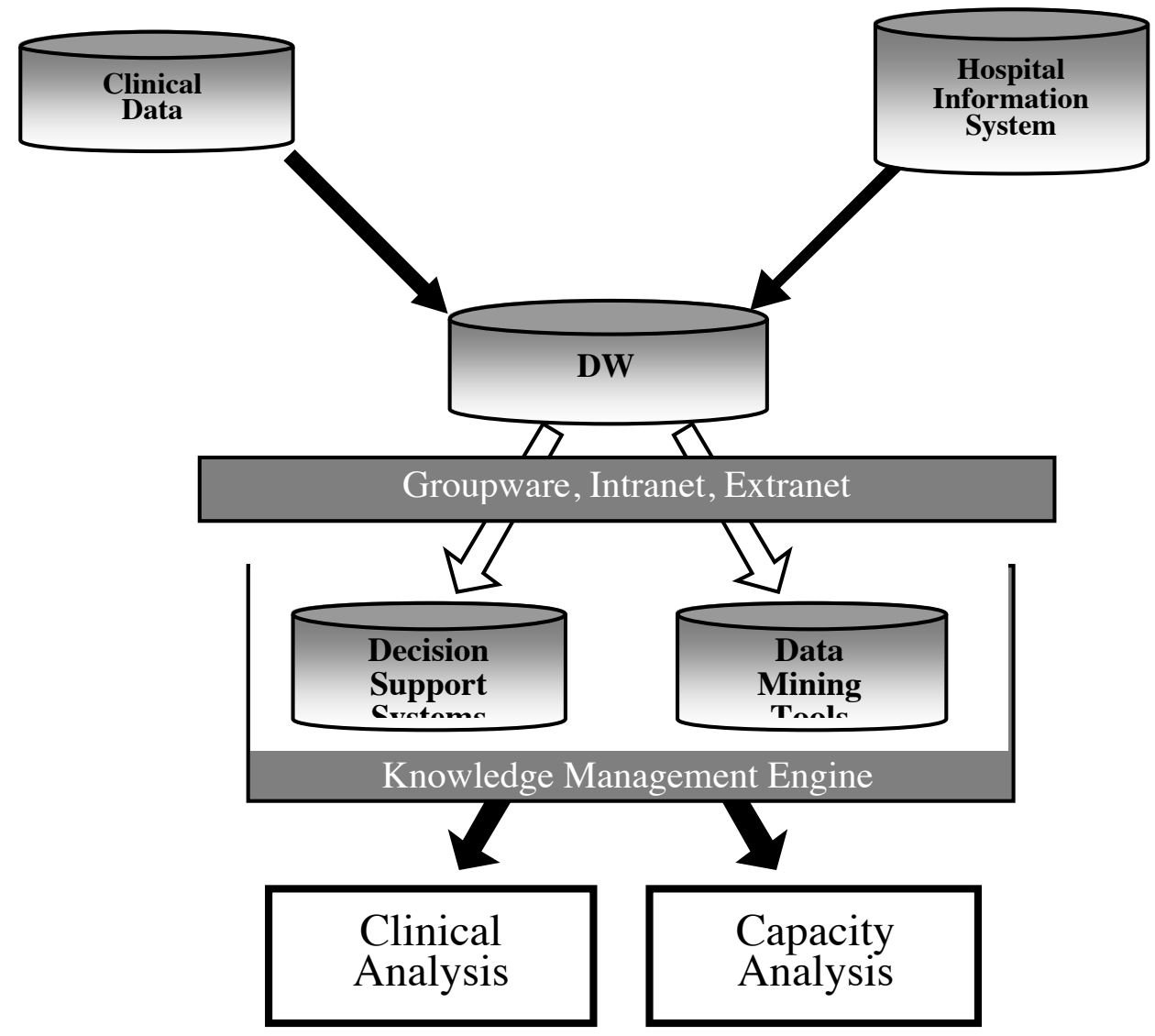

Source: adapted from Bose (2003)

According Hanson (2011), there are relatively few organizations that have developed clinical data warehouses containing patient data related to cancer treatment. Because of the various care practices, data formats and definitions, and the observed incompleteness of clinical information systems, the development of INCA's ICT framework was not an easy task. It can be seen that the development of the framework was quite adequate to the kind of activities proposed by Hull and Tidd (2003) in their model of innovation process: early simultaneous involvement (of physicians, managers, government, suppliers, patients etc), in-process design controls (rapid, reiterative redesign strategy to accommodate development feedback reports) and information and communication technology as support tools.

The definition of the ICT framework was made in five steps:

1. Source: the data sources of the DW, such as OLTP systems and external data sources were defined.

2. Integration: information flow between the data sources and the data warehouse was mapped.

3. Data warehouse: the structure of the data warehouse was designed.

4. Customization: it was defined the mapping between the data warehouse and the clients' structures. 
5. Client: special structures to be used by the users (physicians, staff, managers) to access the data warehouse, such as data marts or OLAP applications, were defined.

The planning phase was decisive and took a lot of time. This was caused by the complexity of the clinical information system and the volume of demands by the final users. Knowledge discovery using association analysis is an iterative procedure demanding medical and IT expert knowledge. Since the objective of the analysis was to extract implicit patterns from among the variables in the dataset, statistical methods and data mining techniques have played a key role.

\subsection{SOURCE}

The clinical data, to be incorporated into the Clinical Cancer Data Warehouse come from Hospital Information System and Clinical Data System as shown in figure 3 and fall into three general categories: (i) the historical information that the patient provides; (ii) the information obtained from physical examination; and (iii) the results of the tests or procedures performed on the patient.

The goal of a hospital information system is to use computers and communications equipment to collect, store, process, retrieve data for all hospital activities, and, at the same time, to satisfy the functional requirements of all authorized users. The system is comprised of patient-oriented modules (admission, discharge, order entry, radiology modules and laboratory modules) and administrative modules (finance and billing, management information and decision-support module).

In the case of INCA, Clinical Data is not included in the HIS since this specific module was customized to fit INCA requirements. The strategic importance of clinical data analysis has motivated INCA to incorporate into the Knowledge Data Warehouse [KDW] the information coming from HIS (patients' demography) and from Electronic Medical Record (EMR) fed by physicians, nurses and other health care providers.

Figure 3: The information pipeline of clinical cancer data integration and preprocessing.

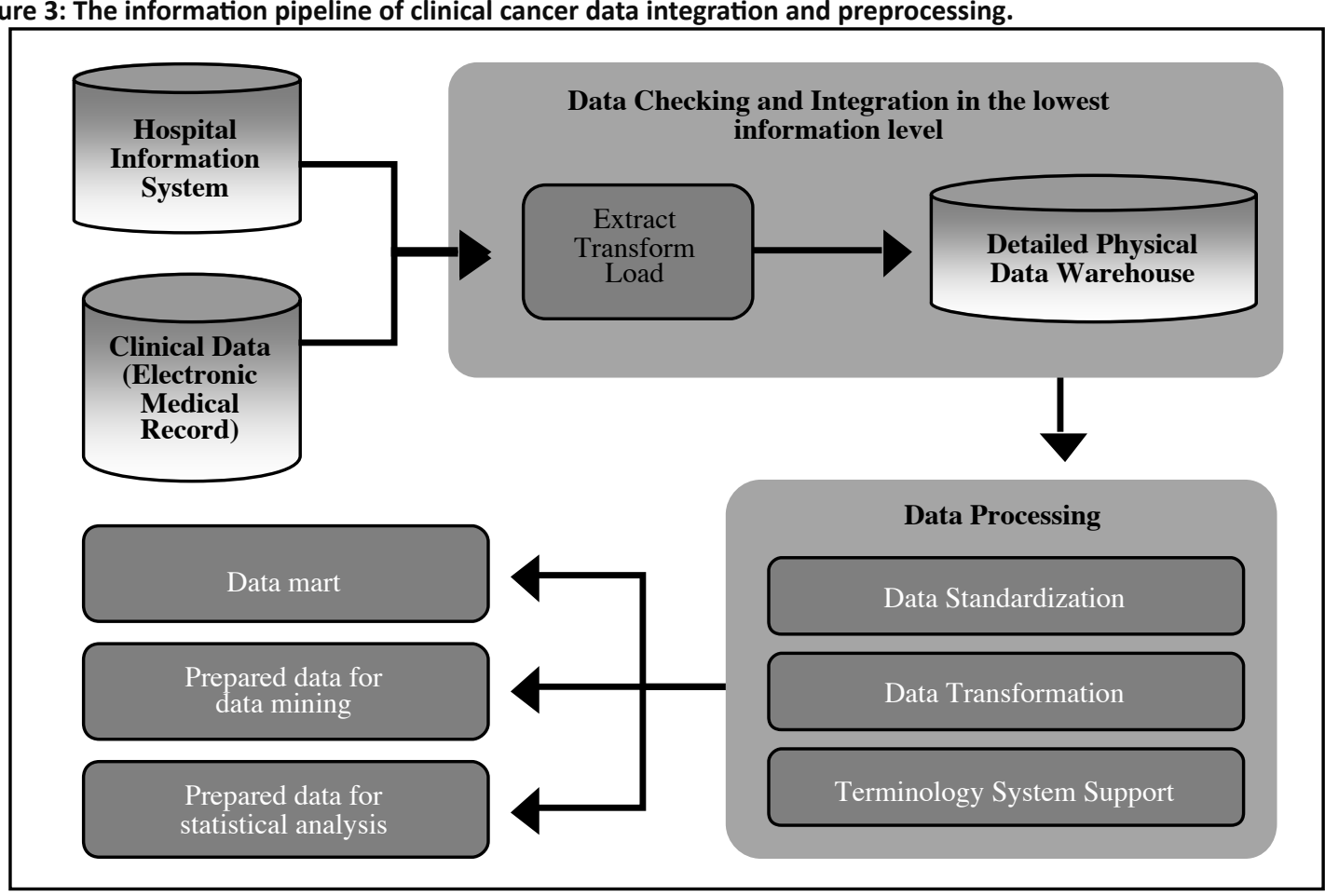

Source: adapted from (Zhou et al., 2010) 


\subsection{INTEGRATION}

Multiple heterogeneous clinical data sources with diverse clinical data standards (e.g. ICD-10, SNOMED-CT) create complications for data integration (Brazhnik, 2007). Consequently, we had to build a unified clinical cancer data warehouse that integrates the data from various data sources with multiple clinical data standards. The implementation in this context was a challenge. It can be seen as an innovative paradigm for the users (physicians and managers) of data from the Electronic Medical Record and Hospital Information Systems.

Physicians, staff and cancer researchers expect to have an integrated environment that provides comprehensive information about cancer cases. Tracking patients and information collection can be very effective in this sense.

\subsection{DATA WAREHOUSE}

According to Zhou and partners (2010), Extraction, Transformation and Loading (ETL) process is the core component of a successful data warehouse system. This can be explained by the requirement of complex clinical data structure transformation, flexible data checking, heterogeneous data sources integration and terminological standardization processing as shown in figure 4. The amount and variety of elements of Figure 4 confirm some of the statements of researchers (Barras, 1986; Hull and Tidd, 2003; Tidd, Bessant and Pavitt, 2005) about the importance of the role of suppliers of hardware and software for healthcare services

Figure 4: The infrastructure of clinical cancer data warehouse

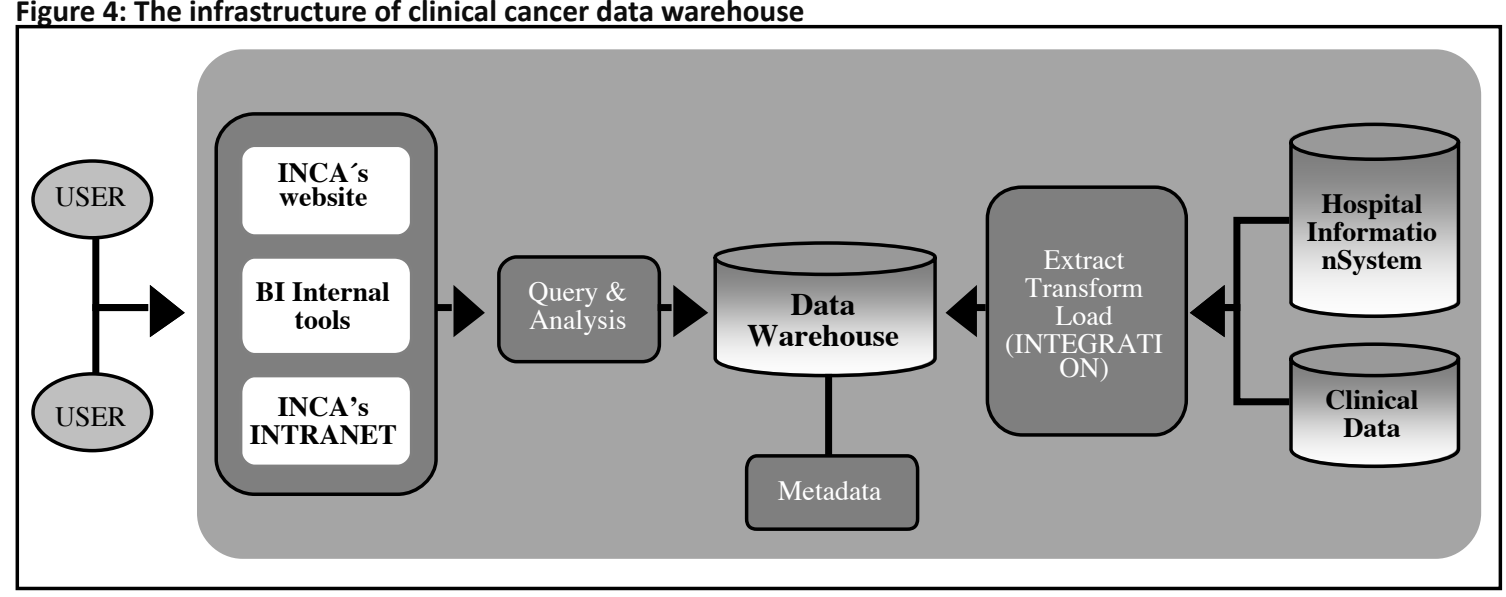

Source: adapted from Zhou and partners (2010)

The Clinical Cancer Data Warehouse information comes from different data sources: (i) the historical information that the patient provides; (ii) the information obtained from physical examination; (iii) the results of the tests or procedures performed on the patient

The data repository is the backbone for all the queries. Data and the analysis queries invoked had to be repetitively analyzed for consistency. The development of the multidimensional data set was carefully planned to appropriately represent the measures of interest. BI tools and decision support technologies help decision makers to assess the performance of INCA practices relative to published guidelines, standards, and evidence.

By utilizing data warehousing concepts and tools, managers have developed their capabilities in the management of medical procedures. If you are evaluating a clinical information sys- 
tem you need to go into details. Specifically, you need to know details regarding patient's record.

In addition to supporting the combined medical and managerial activities, the hospital unit was interested in providing utilization reporting and trend analysis that integrates medical and queue information. The reduction of the patient's waiting time to start cancer treatment plays an increasingly important role in the treatment of this chronic illness.

The three above paragraphs indicate, as stated by Windrum, Garcia-goñi and Fairhurst, (2010), the occurrence at INCA of acquisition of back-office competences by managers and user-facing competences by physicians while using the ICT framework.

\subsection{CUSTOMIZATION}

The description of the development of two different dashboard applications is presented. The first dashboard presents information for queue management at INCA. It was designed to monitor the number of patients waiting to start cancer treatment as shown in the request screen at Figure 5.

Figure 5: Number of Patients Waiting to Start Cancer Treatment

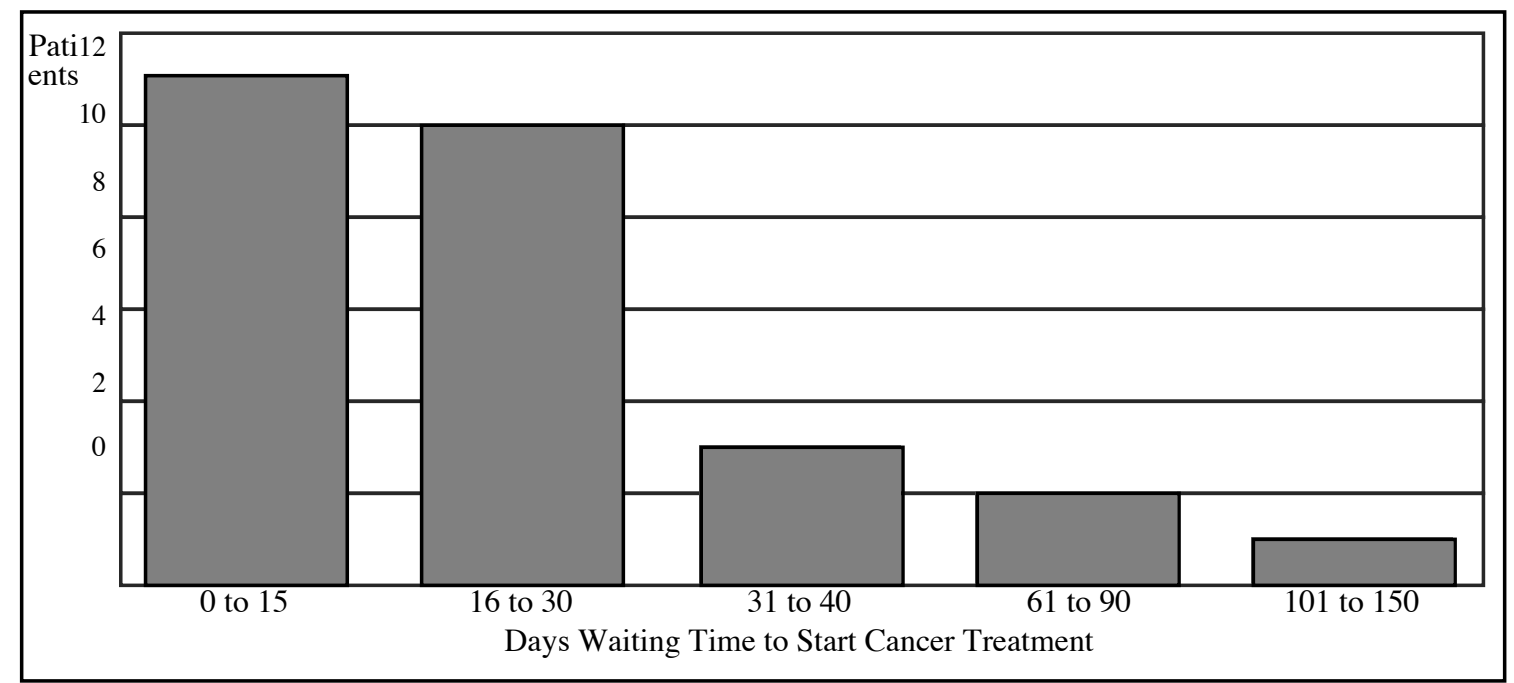

Source: elaborated by the authors.

The second dashboard was designed to monitor the percentage of patients who are waiting for the start of treatment (by type of clinical procedure) as shown in figure 6 . 
Figure 6: Days Waiting Time to Start Cancer Treatment (by type of clinical procedure)

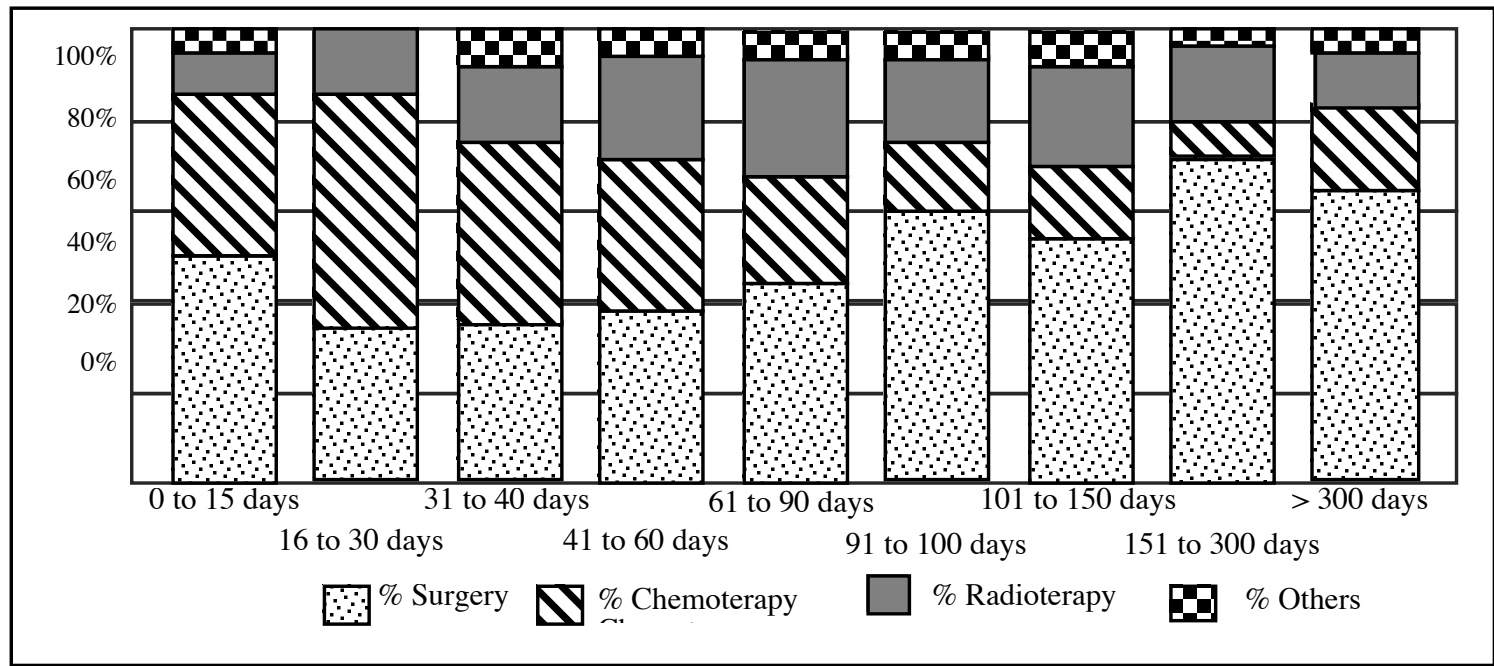

Source: elaborated by the authors.

The two dashboards were designed after specification agreement between users and designers, both concerning monitoring the efficiency of cancer treatment at INCA. The first dashboard was required to evaluate the effectiveness of the queue management while the second makes possible the monitoring and statistical analysis of the percentage of patients who are waiting for the start of treatment (by type of clinical procedure).

According to Passman and partners (2011), this kind of investigation can provide information about the accuracy, effectiveness, efficiency, cost-effectiveness, and impact of clinical outcomes of large population-based cancer early detection programs. It also attends the requirements of policy-makers, one of the aspects mentioned by Windrun and Garcia-Goñi in their model.

These dashboards are dynamic in that they allow exploration of data that may enable to link possible solutions to health problems. The purpose and contents of the dashboard is determined by the clinical team to which the information is most relevant. It must be readily accessible and should evolve based on experience. The user involvement and accessibility as well as the dynamic enquiry should improve the opportunity for feedback to be a regular part of practice management.

Such customization, as suggested by Rogers (2003), contributed for the acceptance of the ICT framework by managers and physicians. This was done by reducing the perception of complexity of the system, and facilitation of the "learning by doing" which helped to reduce the perception of risk of the innovation.

\subsection{CLIENT}

Every clinical department should be interested in quality information and other issues requiring the analysis of patient's data. However, cancer treatment has some characteristics that make clinical data warehouses even more interesting and relevant. A first characteristic is the high availability and dependency on technology and data. Secondly, the cost of and access to cancer treatment units are important management issues. Related to cost and scarcity, a third characteristic of cancer treatment is the obligation to be accountable for the quality of care.

The case study indicates that the ICT framework environment, by providing an innovative approach for clinical knowledge discovery and decision support, contributed to accommodate most of the aspects mentioned in the preceding paragraph. 


\section{CONCLUSIONS}

Cancer research based on real and updated clinical information was the essential requirement for the development of the ICT framework for business intelligence at INCA. The whole framework and the core components, such as clinical information data warehouse, OLAP and Data Mining functions are already implemented.

\section{Critical aspects of the implementation}

Reflection over the outcomes of the ICT framework implementation at INCA shows that:

- Data warehouse development increases requests about system integration and data quality. Mainly data warehouse that use manually patient's data entry like electronic medical record (EMR) fed by physicians, nurses and other health care providers, face quality problems concerning completeness, accuracy and precision.

- Physicians and health care staff are frequently not conscious that the patient's data entry in an electronic record is used for other purposes. If professionals know what they can do with this information, they will be more interested to improve their recording practices.

- Data mining methods can be used to generate new knowledge and insights from large cancer data bases.

- Statistical methods and data mining techniques play a key role in discovering previously unknown knowledge. However, their implementation in this context is difficult.

- In Healthcare the potential to discover unknown association rules and to structure the findings is strong.

- Successful application of data mining techniques requires that experts in healthcare work closely with data mining experts to develop analyses that are relevant to clinical decision making.

\section{Main benefits of the implementation}

Although the process of implementing $\mathrm{BI}$ tools is not trivial and requires careful planning and significant work from a multidisciplinary group, the benefits that can be achieved by better informing and guiding decisions are expected to outweigh the costs. By providing on-demand answers to relevant questions, these tools will be an important factor for performance improvement in practices.

The main benefits derived from implementation of this ICT framework for cancer disease information management, so far, are:

- Real-time knowledge access ;

- Patient's focus and satisfaction;

- enhanced knowledge transfer and diffusion of best healthcare practices;

- Reduction in treatment costs;

- Relief of the INCA's labor shortage; and finally

- Speediness of cancer diagnosis and enhanced quality of both diagnosis and data used in epidemiological studies,

Therefore, the first results indicate that the implementation of the ICT framework has improved firstly, as suggested by Barras (1996), the efficiency of existing services delivery process, secondly the quality of existing services, and in the future it is hoped that it will contribute for the development of new healthcare services. 
As a future research, we suggest to investigate how the ICT framework is going to deal with the task of incorporating the preferences and competences of patients (users), which is also a relevant aspect of the Windrun and Garcia-Goñi model for innovation process.

\section{REFERENCES}

$\mathrm{BACH}, \mathrm{M}$. Data mining applications in public organizations. In Proceedings of the 25th international conference on information technology interfaces (pp. 211-216), 2003.

BARRAS Richard. Towards a theory of innovation in services. Research Policy, 15, 161-173, 1986.

BERNDT D.J., HEVNER A.R., STUDNICKI J. The catch data warehouse: support for community health care decision-making. Decision Support Systems, 35(3):367-84, 2003.

BOSE, R. Knowledge management-enabled health care management systems: capabilities, infrastructure, and decision-support. Expert Systems with Applications, 24(1), 59-71, 2003.

BRAZHNIK O, JONES JR. Anatomy of data integration. J Biomedical Information, 40 (June (3): 252-69, 2007.

COOPER, D. R., SCHINDLER, P. S. Métodos de pesquisa em administração (7a ed.). Porto Alegre: Bookman, 2003.

DAMANPOUR, F; SCHNEIDER, M. Phases of the adoption of innovation in organizations: effects of environment, organization and top managers. British Academy of Management, v. 17, 3, p. 177-260, 2006.

DELEN D; WALKER G; KADAM A.; Predicting breast cancer survivability: a comparison of three data mining methods. Artificial intelligence in medicine, Jun;34(2):113-27, 2005.

DEMIRHAN, D.; JACOB, V.; RAGHUNATHAN, S. Information technology investment strategies under declining technology cost. Journal of Management Information Systems, 22(3), 321350, 2006.
DUTTA, A, HEDA, S. Information systems architecture to support managed care business process, Decision Support Systems, 30, pp 217 225, 2000.

FAYYAD, U. M.; PIATETSKY-SHAPIRO, G.; AND SMYTH, P. From Data Mining to Knowledge Discovery: An Overview. In Advances in Knowledge Discovery and Data Mining, eds. U. Fayyad, G. Piatetsky- Shapiro, P. Smyth, and R. Uthurusamy, 1-30. Menlo Park, Calif.: AAAI Press, 1996.

FICKENSCHER, K. M. The new frontier of data mining. Health Management Technology, 26(10), 26-30, 2005.

GINIAT, E. (2011). Using business intelligence for competitive advantage. Healthcare Financial Management, 65(9), 142, 144, 146, 2001.

GOEBEL, M., \& GRUENWALD, L. A survey of data mining and knowledge discovery software tools. ACM SIGKDD, 1(1), 20-33, 1999.

HANSON, R. (2011). Good health information - An asset not a burden!. AustralianHealth Review, 35(1), 9-13, 2001.

TIDD J.; HULL F. M. Service Innovation: organizational responses to technological opportunities and market imperatives. London: Imperial College Press, 2003.

HULL, F. M. A Composite Model of Product Development Effectiveness: Application to Services. IEEE Transactions on Engineering Management, vol. 51, n. 2, may 2004.

LENZ R., KUHN K.A.Towards a continuous evolution and adaptation of information systems in healthcare. International Journal of Medical Informatics, 73 (1), 75-89, 2004.

LESTER $\mathrm{H}, \mathrm{HOBBS}$ FDR. Of family medicines from the quality and outcomes framework in 
the United Kingdom. Fam Med ;39(2):96-102, 2007.

LIAW SS. Understanding user perceptions of world-wide web environments. J ComputAssist Learn;18(2):137-48, 2002.

METTLER, T., \& VIMARLUND, V. Understanding business intelligence in the con-text of healthcare. Health Informatics Journal, 15(3), 254-264, 2009.

PASSMAN, L., FARIAS, A. R., TOMAZELLI, J. G. , ABREU, D., DIAS, M. B. K, SANTINI, L. A. SISMAMA--implementation of an information system for breast cancer early detection programs in Brazil. Breast (Edinburgh, Scotland), 20 (2), p.35-39, 2011.

RICHARDS, G., RAYWARD-SMITH, V.J., SÖNKSEN, P.H., CAREY, S., WENG, C. Data mining for indicators of early mortality in a database of clinical records. Artificial Intelligence in Medicine, 215-231, 2001.

ROGERS, E. M. Diffusion of Innovations. Free Press, Ney York, 2003.

ROHLOFF, R. Health-care BI: A tool for meaningful analysis. Healthcare Financial Management, 65(5), 100-108, 2011.

ROSS, J. W., WEILL, P.; ROBERTSON, D. C. Arquitetura de TI como Estratégia Empresarial. São Paulo: M. Books, 2008.

SHAMS K., FARISHTA M. Data Warehousing: Towards knowledge management. Top Health Information Management. Feb, 21 (3): 24-32, 2001.

SHENG, O R Liu Decision support for healthcare in a new information age. Decision Support Systems, 30, pp101-103, 2000.

TIDD J.; BESSANT J. Managing Innovation: integrating technological market and organizational change. Chichester: John Willey \& Sons Ltd, $4^{\text {th }}$ ed., 2009.

ZHOU X., CHEN S., LIU B., ZHAN R., WANG
Y., P. LI, GUO Y., ZHANG H., GAO, YAN X. Development of traditional Chinese medicine clinical data warehouse for medical knowledge discovery and decision support. Artificial Intelligence in Medicine,48, 139-152, 2010.

VARKEY, P., A. HORNE,AND K.E. BENNET. (2008). Innovation in Health Care: a primer. American Journal of Medical Quality, vol. 23: 382-388, 2008.

WINDRUM P., GARCIA-GOÑI M. and FAIRHURST E. Innovation in public health care: diabetes education in the UK. In: GALLOUJ F., DJELLAL F. The Handbook of Innovation and Services: a multi-disciplinary perspective. Cheltenham, UK: Edward Elgar, 2010, p. 134-135.

YIN, R. K. Case study research: design and methods (3rd ed.). Thousand Oaks, CA: Sage, 2003. 